\title{
AS RELAÇÕES ENTRE DIREITOS HUMANOS E PRÁTICAS DOS POLICIAIS CIVIS: O PAPEL DA PERCEPÇÃO DOS CIDADÃOS ${ }^{1}$
}

\author{
Ludmila Mendonça Lopes Ribeiro \\ Klarissa Almeida Silva
}

\begin{abstract}
Resumo
Como os cidadãos percebem as práticas dos policiais civis? Esses entendimentos têm alguma conexão com o conceito de direitos humanos? Em que medida os cidadãos creditam à Polícia Civil importante papel na materialização da ideia de direitos humanos, entendidos como "mecanismos capazes de prover tratamento igual aos diferentes, universalizando a aplicação da lei às distintas identidades que se especificam no espaço público" (KANT DE LIMA, 2004)? Para responder a essas questões foram utilizadas informações (dados quantitativos e qualitativos) coletadas no âmbito da III Semana de Visitas a Delegacias de Polícia (2009). A partir dessas informações, este artigo discute em que medida as práticas dos policiais civis, no Brasil, se coadunam ou não com o que se entende por direitos humanos no cenário atual.
\end{abstract}

Palavras-Chave: Semana de Visitas a Delegacias de Polícia; Direitos Humanos; Práticas Policiais.

\begin{abstract}
How do citizens perceives the civil police practices? Do these understands have any connection with the concept of human rights? In which extent do citizens credited to the Civilian Police some role in materializing the idea of human rights, understood as "mechanisms capable of providing equal treatment to different universalizing law enforcement to the different identities that are specified in the public space" (KANT DE LIMA, 2004)? To answer these questions we used data (quantitative and qualitative) gathered under III Police Station Visitors Week (2009). From this information, this paper discusses in which extension the civil policeman practices fit (or not) with the understanding of human rights in the actual scenario and how they can be transformed to promote this adequacy.
\end{abstract}

Keywords: Police Station Visitors Week; Human Rights; Police Practices.

\section{Introdução}

O tema da segurança pública se situa entre as primeiras preocupações da opinião pública dos brasileiros. Como as polícias são as faces mais visíveis dessa questão, é importante compreender como os cidadãos avaliam a sua performance, pois a partir dessa percepção,

\footnotetext{
1 Uma primeira versão desse trabalho foi apresentada na $27^{\mathrm{a}}$. Reunião Brasileira de Antropologia, realizada entre os dias 01 e 04 de agosto de 2010, Belém, Pará, Brasil. As autoras agradecem aos debatedores as sugestões e os comentários que contribuíram para essa versão final.
} 
torna-se possível desenhar políticas que permitam a prestação de um serviço policial mais condizente com o moderno entendimento do termo direitos humanos, qual seja: "mecanismos capazes de prover tratamento igual aos diferentes, universalizando a aplicação da lei às distintas identidades que se especificam no espaço público" (KANT DE LIMA, 2004).

No que se refere à percepção que os indivíduos possuem da Polícia Civil, de acordo com dados publicados recentemente pelo IPEA $(2010)^{2}$, tem-se que $4,0 \%$ confiam muito, $26,1 \%$ confiam, $44,0 \%$ confiam pouco e $25,9 \%$ não confiam. Logo, $69,9 \%$ da população apresentam algum grau de desconfiança em relação à Polícia Civil. Quando indagados a respeito da qualidade dos serviços prestados pelas instituições policiais, a maior parte dos entrevistados manifestou insatisfação com sua forma de atuação, além de identificar elementos como preconceito e desrespeito aos direitos do cidadão no atendimento policial em geral. Em suma, de acordo com a pesquisa do IPEA, a avaliação geral dos serviços comumente prestados pelas instituições policiais é negativa (IPEA, 2010).

Assim, entendendo que os direitos humanos "constituem o principal instrumento de defesa, garantia e promoção das liberdades públicas e das condições materiais essenciais para uma vida digna" e que "o Brasil só poderá concretizar seu projeto de democratização prescrito pela Constituição quando os direitos humanos alcançarem concretamente o cotidiano dos indivíduos com plena força normativa" (CUNHA, 2005, p. 139-144), este artigo se utiliza das impressões de centenas de cidadãos brasileiros sobre a rotina de 235 delegacias situadas em distintas regiões do país para discutir em que medida os policiais civis têm sido capazes de garantir e respeitar os direitos humanos de todos os que procuram uma unidade dessa natureza.

Os dados analisados nesse paper foram coletados no âmbito da

2 Os dados aqui apresentados são resultantes da análise do Sistema de Indicadores de Percepção Social. Desenvolvidos pelo IPEA, esses são destinados a verificar como a população avalia os serviços de utilidade pública e o grau de importância deles para a sociedade. Uma das mensurações realizadas nesse projeto foi a relacionada ao grau de confiança que a população deposita na Polícia Civil. 
III Semana de Visitas a Delegacias de Polícia (2009), uma pesquisa desenvolvida pela Altus Aliança Global ${ }^{3}$ com o objetivo de levar cidadãos de diversos países às delegacias de polícia para avaliá-las quanto a: 1) orientação para a comunidade; 2) condições materiais; 3) tratamento igualitário do público; 4) transparência e prestação de contas; 5) condições de detenção.

Para que a pesquisa pudesse funcionar de maneira global, era necessário fornecer instruções e informações comuns a todos os participantes, de tal maneira que estes pudessem observar os mesmos itens em todas as localidades. Para desenvolver esta ferramenta, a Altus mobilizou uma equipe de pesquisadores de vários países, consultou as legislações internacionais sobre o assunto $^{4}$ e a bibliografia existente sobre padrões de policiamento. A partir da análise destes materiais, foram formuladas 20 perguntas básicas que poderiam ser entendidas da mesma forma em contextos culturais distintos. Contudo, para se garantir que as opiniões e impressões dos visitantes pudessem ser registradas de maneira diferenciadas, esse formulário contava ainda com uma seção aberta, na qual o visitante deveria registrar livremente as suas impressões.

Este primeiro instrumento foi testado em oito países, sendo que

\footnotetext{
${ }^{3}$ A Altus é uma aliança global que atua em vários continentes e adota uma perspectiva multicultural para melhorar a segurança pública e o sistema de justiça criminal. Seu principal projeto é a Semana de Visitas, organizado para: 1) avaliar a qualidade de serviços prestados por departamentos de polícia; 2) identificar boas práticas policiais; 3) fortalecer a prestação de contas pela polícia no que diz respeito ao público a que ela serve; 4) promover os direitos humanos. São membros fundadores da Altus: Centro de Estudos de Segurança Cidadã (Brasil); Centro de Estudos de Segurança e Cidadania (Chile); Fundação CLEEN (Nigéria); Instituto de Desenvolvimento e Comunicação (Índia); Fundação INDEM (Rússia); Instituto de Justiça VERA (Estados Unidos da América). Para maiores informações: <http://www.altus.org>.

4 Essas perguntas foram construídas a partir da consulta aos dispositivos de tratados internacionais sobre como as delegacias de polícia devem funcionar no sentido de garantirem um tratamento igualitário dos indivíduos que procuram essas organizações para registrarem crimes ou fornecerem informações sobre delitos de que foram vítimas ou testemunhas. Entre os principais diplomas consultados nesse sentido têm-se os seguintes: 1) United Nations Body of Principles for the Protection of all Persons Under any Form of Detention or Imprisonment; 2) United Nations Convention on the Elimination of All Forms of Discrimination Against Women; 3) United Nations Covenant on Civil and Political Rights (ICCPR); 4) United Nations Declaration of Basic Principles of Justice for Victims of Crime and Abuse of Power (Victims Declaration); 5) United Nations Declaration on the Elimination of All Forms of Racial Discrimination (CERD); 6) United Nations Declaration on the Protection of All Persons from Enforced Disappearance; 7) United Nations Standard Minimum Rules for Non-custodial Measures (the Tokyo Rules); 8) Universal Declaration of Human Rights.
} 
os resultados obtidos demonstraram que esta ferramenta era, de fato, capaz de alcançar os objetivos propostos de avaliação da qualidade do serviço prestado pelas delegacias de polícia. Ao final (em 2004), este primeiro questionário foi disponibilizado no site das organizações que participaram do projeto e no site da Altus.

Neste mesmo ano, o Governador do Estado do Ceará, Lúcio Alcantara, encontrou o questionário no site da Altus e perguntou se poderia utilizá-lo para avaliar as delegacias da capital do estado Fortaleza. O mesmo ocorreu com o Departamento de Segurança Pública da África do Sul, que se interessou em utilizar o questionário para avaliar o funcionamento de suas organizações policiais. A partir dessas demandas, a Altus decidiu transformar a utilização da ferramenta em um acontecimento global que congregasse, simultaneamente, instituições de pesquisa e cidadãos, potenciais usuários do serviço prestado pela delegacia de polícia. Com o financiamento do Open Society Institute e do United Kingdom Department for International Development (DFID), a Semana de Visitas a Delegacias de Polícia pôde ser realizada nos anos de 2006, 2007 e 20095.

No ano de 2009, foram visitadas 1.051 delegacias de polícia distribuídas em 20 países. No Brasil, foram visitadas 235 delegacias distribuídas em 11 cidades/regiões metropolitanas. As unidades visitadas foram sorteadas aleatoriamente: 20 delegacias distritais $^{6}$ e 1 Delegacia Especializada de Atendimento à Mulher (DEAM) em cada uma das capitais e regiões metropolitanas. Em São Paulo e no Rio de Janeiro, em virtude do tamanho da população e do número de delegacias ${ }^{7}$, foram sorteadas 40 delegacias e 2 DEAMs. Devido ao movimento de indivíduos, que pediram para visitarem as delegacias, por acreditarem ser a Semana de Visitas um importante mecanismo de accountability

\footnotetext{
5 Este instrumento encontra-se reproduzido no site <http://www.altus.org>. Importante destacar ainda que no momento de revisão deste artigo a IV Semana de Visitas a Delegacias de Polícia já tinha se realizado entre os dias 18 e 24 de outubro de 2010.

6 Este quantitativo foi estabelecido levando-se em consideração a informação repassada pela Diretoria de Estudos e Pesquisas da Secretaria Nacional de Segurança Pública do Ministério da Justiça de que este é o número médio de delegacias tradicionais (ou não especializadas) existente nas diversas regiões metropolitanas brasileiras.

7 Já que essas duas cidades concentram quase metade do total de delegacias distritais existentes em todo o país.
} 
outras quatro delegacias foram incluídas na amostra: uma no Rio de Janeiro, uma em Juruti (Pará) e duas em Pelotas.

Para a visita simultânea a todas essas unidades, foi criada uma rede de centros de pesquisa, coordenada pelo Centro de Estudos de Segurança e Cidadania $(\mathrm{CESeC})^{8}$ e integrada pelos seguintes institutos: Núcleo de Estudos da Cidadania, Conflito e Violência Urbana (RJ), Instituto Sou da Paz e Núcleo de Estudos da Violência (SP), Centro de Estudos da Criminalidade e Segurança Pública (MG), Núcleo de Estudos sobre Violência e Segurança (DF), Núcleo de Estudos em Criminalidade, Violência e Políticas Públicas de Segurança (PE), Instituto de Acesso à Justiça (RS), Laboratório de Estudos da Violência (CE), Universidade Federal do Pará (PA) e Universidade Federal de Goiás (GO).

Uma vez estabelecida a parceria, cada centro de pesquisa designa um (ou dois, como em São Paulo) pesquisador para ocupar a função de coordenador regional da pesquisa naquela capital e este, por sua vez, seleciona os coordenadores das visitas, estudantes da graduação ou mestrado que devem escolher os visitantes. Essas funções devem ser destacadas porque cada delegacia é visitada por um grupo de cinco pessoas (o coordenador e quatro visitantes, neste caso, cidadãos comuns), sendo que cada grupo pode visitar até três delegacias. Ao final, no ano de 2009, as delegacias brasileiras receberam 1.164 visitantes ${ }^{9}$.

Para se garantir que todos os grupos avaliem as delegacias de polícia da mesma forma, o representante regional da Altus treina diretamente os coordenadores de visita, já que esses devem atuar como multiplicadores, não apenas recrutando voluntários como ainda os treinando no uso do questionário padrão. Na Semana de Visitas (que é a mesma em todos os locais do mundo), os cidadãos se dirigem às delegacias no dia e hora combinados previamente com os policiais (já que o propósito não é surpreendê-los, mas avaliar as suas condições de

8 o Centro de Estudos de Segurança e Cidadania, da Universidade Candido Mendes, é o coordenador nacional da pesquisa por ser o membro fundador da Altus.

${ }^{9}$ Lembrando que, nesse caso, a unidade é visitante e não indivíduo e, como um indivíduo pode visitar até três delegacias, ele pode ser contado até três vezes nesse número global que se apresenta. 
trabalho) e lá permanecem por, em média, uma hora e meia, apenas observando, conversando com policiais e cidadãos que aguardam para serem atendidos e fotografando as condições da unidade. Após as visitas, os participantes se reúnem para responder às questões quantitativas (20 perguntas divididas em cinco blocos de quatro questões), sendo que estas, juntamente com os relatórios qualitativos, são inseridas no site da Altus para o cálculo das notas de cada delegacia e a consolidação dos resultados.

A grande inovação dessa pesquisa é o fato de os dados serem coletados pelos próprios usuários do serviço, colocando, portanto, novas questões em relação aos estudos tradicionalmente desenvolvidos nesta seara com o uso da etnometodologia enquanto estratégia de pesquisa ${ }^{10}$. Afinal, tal como destacado por Manning (2009), as atividades da polícia apenas podem ser adequadamente compreendidas quando a rotina dos policiais, no cumprimento de sua missão institucional, é acompanhada, já que a ação policial é o resultado combinado de regras, atividades verbais e, sobretudo, atividades não verbais.

Logo, a perspectiva etnomedológica se mostra bastante útil para estudos dessa natureza por colocar ênfase nos processos interativos, especialmente, os que dizem respeito à fala e à conversação, fenômenos que expressam o entendimento que esses fazem do mundo exterior. Neste sentido, enquanto arcabouço metodológico, ela enfatiza a importância de se acompanhar a forma como os atores constroem normas e regras que utilizam rotineiramente para que seja possível a sua adequada compreensão em termos do significado que eles empregam a estas.

Nesses termos, a Semana de Visitas a Delegacias de Polícia se apresenta enquanto pesquisa que utiliza a etnometodologia, posto que os visitantes devem permanecer por um tempo na delegacia, analisando e descortinando os significados que os policiais concedem às suas

10 De acordo com Giddens e Turner (1999, p.14), "os etnometodologistas, em geral, defendem a descrição pormenorizada de processos empíricos, aparentemente desconsiderando o que constituiria a explicação ou a cientificidade da descrição". Exatamente por isso, acredita-se que os dados coletados no âmbito da Semana de Visitas a Delegacias de Polícia podem ser considerados válidos e produzidos dentro da lógica de pesquisa da etnometodologia. 
práticas. Apenas após tais procedimentos é que eles podem preencher os questionários qualitativos e quantitativos de avaliação da qualidade do serviço que a delegacia presta aos cidadãos, momento em que diversos visitantes fazem referência aos direitos humanos que não se materializam nessas unidades.

Assim, para a realização dessa análise, além desta introdução, o artigo encontra-se estruturado em três seções. A primeira procura elucidar as questões que a Semana de Visitas a Delegacias de Polícia acrescenta em relação aos estudos tradicionalmente realizados sobre funcionamento das organizações policiais no Brasil. A partir da problematização dos dados coletados na Semana de Visitas, a segunda seção é estruturada com o objetivo de se denotar em que medida as práticas dos operadores de polícia civil, no Brasil, se coadunam ou não com o que se entende por direitos humanos no cenário atual. Por fim, os resultados de ambas as seções são problematizados com o objetivo de se apontar caminhos para uma moderna articulação entre entendimento do conceito de direitos humanos e práticas policiais.

\section{Os estudos tradicionais sobre organizações policiais e as contribuições da Semana de Visitas a Delegacias de Polícia}

Este artigo tem como ponto de partida as discussões socioantropológicas sobre funcionamento das organizações policiais no contexto latino-americano em geral e brasileiro em especial, tal como recentemente revisadas e resumidas por Frühling (2009). De maneira sucinta, o artigo deste pesquisador aponta para os problemas que a transição do militarismo para o modelo profissional de polícia ainda não foi capaz de solucionar, especialmente, no que diz respeito ao elevado uso discricionário da força que, por sua vez, compromete sobremaneira a capacidade das organizações policiais em materializarem o conceito de direitos humanos.

Desde os anos 1970, os estudos realizados sobre o tema têm colocado especial importância no entendimento de (1) práticas policiais discriminatórias que terminam por criminalizar a pobreza (COELHO, 1980); (2) desmistificação do corporativismo policial que, em boa 
medida, procura encobrir os delitos de corrupção cometidos por esses agentes (PAIXÃO, 1982); (3) efeitos acumulados que esses procedimentos possuem no grau de confiança que a população deposita nessa agência e, por conseguinte, na probabilidade dos indivíduos procurarem esse órgão quando vítimas de um crime (KANT DE LIMA, 1989). Nesse último caso, distintos estudos têm salientado que abordar os números produzidos pelas polícias como reflexo do que ocorre na sociedade em termos de crime e desordem pode ser um equívoco, dado que os problemas anteriormente apontados contribuem para uma subnotificação, em algumas situações, excessivamente elevada (FRÜHLING, 2009).

Neste contexto, Manning (2009) afirma que não é possível compreender o que a polícia faz, como ela faz e quando faz apenas a partir da análise dos registros que ela produz. É preciso ir além, compreendendo especialmente o que ele denomina de poética da comunicação policial - que nada mais é do que as demonstrações que os policiais produzem acerca do que fazem e do que pensam sobre sua atividade de policiamento ${ }^{11}$.

Para tanto, um instrumento que tem se mostrado extremamente frutífero neste sentido é etnometodologia, técnica que empresta especial importância não apenas aos processos comunicacionais, mas ainda à forma como os indivíduos desvelam o sistema de crenças, valores e atitudes organizacionais em seu trabalho cotidiano. Exatamente por isso o autor enfatiza que os estudiosos do tema devem se empenhar na rerealização de trabalhos sobre a polícia para que seja possível avançar no conhecimento do tema e, por conseguinte, na elaboração de políticas públicas para o setor. Ou, como o próprio Manning (2009, p. 417) destaca, "important discoveries need to be rediscovered".

Para situar a questão dos direitos humanos nesse contexto de pesquisa, é importante destacar, como bem realiza Holanda (2005), que este termo traz em si uma expectativa de indistinção entre os homens

\footnotetext{
11 No original: "the question of what Police do, how well, why, and when cannot be answered by what they choose to record and account for. They have no responsibility to record all that is seen, said, heard or smelt" (MANNING, 2009, p. 455).
} 
no que se refere à aplicação das regras. Contudo, o mandato policial, especialmente em sua dimensão de aproximação/atendimento da comunidade, implica em flexibilidade para adaptar a lei às demandas e expectativas locais. Esse cenário de fluidez normativa para adequar as demandas diferentes dos distintos indivíduos, por sua vez, está em claro desacordo com o princípio de tratamento igualitário dos homens. Nesse sentido, a questão passa a ser como as organizações policiais equilibram essas duas dimensões de maneira a garantir a aplicação da lei universal às distintas identidades que se especificam no espaço público.

Nesse sentido, tal como destacado por Bayley e Bittner (1986) torna-se importante compreender como os policiais se comportam nos três estágios de sua interação com os cidadãos, quais sejam: contato, processamento e saída. Cada etapa do contato implica em distintas ações, expressões e palavras que revelam, de fato, o que a polícia, em sentido geral e o policial em especial pensam da situação.

Boa parte dos estudos realizados no Brasil que buscou compreender a prática dos operadores da justiça utilizou-se da etnometodologia (SUDNOW, 1965; GARFINKEL, 1967; CICOUREL, 1968). Em linhas gerais, estas análises mostram que é no âmbito de tais organizações profissionais que se pode perceber de forma mais nítida a estandardização e a institucionalização de certos códigos de tipificação (SCHUTZ, 1979).

Esse processo de tipificação é importante porque, em regra, os policiais trabalham de acordo com estereótipos previamente estabelecidos sobre quem são os criminosos (RAMOS e MUSUMECI, 2005), partindo, portanto, do indivíduo para o crime (PAIXÃO, 1982) como forma de garantir a eficiência do sistema de justiça criminal (SAPORI, 1995). Daí porque a maioria dos policiais entrevistados em pesquisas dessa natureza afirma que quando um procedimento qualquer é iniciado (como registro de ocorrências ou mesmo inquérito policial), ele também já está concluído, pois já se sabe quem será incriminado com essa atividade (MISSE, 1999).

Contudo, se de um lado, há o estereótipo do criminoso - o pobre, o preto, o vagabundo - também há, de outro lado, o estereótipo da 
"polícia brasileira" como uma organização violenta, corrupta, ineficiente e violadora dos direitos humanos, entre outros atributos (NASCIMENTO, 2003).

Nesse sentido, as delegacias de polícia emergem como cenários de especial importância na medida em que os seus serviços contribuem ou para a desconstrução de estereótipos ou para a sua reificação. Essa visão das delegacias também afeta os números produzidos por ela. Assim, tal como destacado por Soares (2000), se as delegacias atendem melhor e a confiança na polícia aumenta, os cidadãos tendem a denunciar mais os crimes de que foram vítimas, o que, por sua vez, provoca um crescimento do número dos registros de crimes, ainda que a quantidade de crimes permaneça inalterada. O que muda quando os cidadãos acreditam que as agências polícias agem de acordo com os princípios dos direitos humanos é que os registros policiais passam a corresponder, de maneira mais fidedigna, ao que ocorre na realidade social (reduzindo, portanto, a distância entre registros e práticas policiais a que Mainning se refere).

Neste sentido, a Semana de Visitas a Delegacias de Polícia se apresenta como uma contribuição aos estudos dessa área na medida em que permite uma reflexão sobre como os próprios cidadãos percebem as práticas policiais e sua consonância (ou não) com a definição de direitos humanos.

Os dados coletados nessa pesquisa, contudo, reforçam o entendimento de Nascimento (2003), já que a população avalia a polícia negativamente, identificando-a como agência desrespeitadora dos direitos humanos, mesmo quando nunca tiveram contato com essa organização, tal como denotam as seguintes citações ${ }^{12}$ :

A visão de uma polícia desinteressada foi um pouco modificada pela visão de uma polícia sem recursos, sem incentivo que tenta se adaptar as condições adversas (Relatório narrativo da visita à delegacia A14, em Goiânia).

12 Todas essas citações foram retiradas dos relatórios narrativos, feitos pelos coordenadores de visitas. Assim, as delegacias foram numeradas de maneira a não serem identificadas diretamente (ALTUS, 2006). 
A visita foi de grande relevância para todos os integrantes da equipe, no qual, foi possível notar as reais condições dos serviços prestados na seccional. Por fim, a seccional atende as necessidades básicas da comunidade (Relatório narrativo da visita à delegacia A18, em Belém do Pará).

Um fato que chamou a atenção de todos foi o delegado ser negro. Por mais que não sejamos preconceituosos, o fato nos surpreendeu por não ser tão usual, pelo menos em nossa visão. A visita anterior ajudou a mudar nossa visão. Ninguém sentiu medo ou se sentiu coagido por estar ali, os policiais não nos trataram como se fossem seres superiores e nós inferiores (Relatório narrativo da visita à delegacia A32, no Rio de Janeiro).

Contudo, é importante salientar que essa interação possui como externalidade positiva a possibilidade de contribuir para a desmistificação de estereótipos e, por conseguinte, aumento da confiança da população na polícia.

Os visitantes saíram de lá com uma boa impressão da Delegacia. Eu tive a impressão de que essa visita criou nos visitantes uma sensação de confiança na polícia. Creio que em casos futuros em que esses visitantes precisem acionar a polícia, eles não hesitarão (Relatório narrativo da visita à delegacia A183, em Brasília).

A equipe de visitantes declarou estar feliz por participar do projeto, tendo a oportunidade de conhecer e entender como é a estrutura de funcionamento de uma delegacia. Alguns relataram se sentir mais seguros, após a visita, de irem a uma delegacia futuramente, outros se decepcionaram com a estrutura encontrada e declararam ter diminuído a confiança que depositavam anteriormente na policia (Relatório narrativo da visita à delegacia A11, em Recife).

Claro que, dependendo da unidade policial em questão, nem sempre é possível alcançar tal objetivo e, com isso, a participação do indivíduo na pesquisa termina por reforçar a imagem negativa que os cidadãos possuem dessa organização:

Apesar de termos uma expectativa negativa inicial, ela piorou após a visita. Vimos a precariedade em seu estado concreto e como as pessoas da circunscrição 
estão desamparadas, pois os equipamentos são precários e a eficiência de resolução dos crimes é muito baixa, como apresentada pelo próprio investigador. $\mathrm{O}$ visitante 01 ficou muito assustado com a delegacia, deu ênfase para a sua surpresa e a calamidade em que esta se encontra. A visitante 02 acreditava encontrar uma situação precária, mas não imaginava tamanha desestrutura. A visitante 03 piorou sua visão sobre a delegacia, disse que imaginava um mínimo de estrutura e de recepção dos funcionários, destacou a vulnerabilidade dos usuários, que estão mais ameaçados do que protegidos pela delegacia nessas condições e viu a presença da Polinter ali, sem nenhuma segurança, como um risco eminente para a delegacia e para a região. O visitante 04 já conhecia a delegacia, pois registrou um furto de documentos no ano passado, mas não imaginava que até os funcionários estavam sujeitos às mesmas condições caóticas experimentadas pelos usuários (Relatório narrativo da visita à delegacia A28, no Rio de Janeiro).

Para alguns dos visitantes, a visita serviu apenas para confirmar suas expectativas negativas sobre o local, para outros a situação encontrada é pior do que imaginavam. As condições do prédio e da carceragem impressionaram negativamente. Além disso, acreditam que o fato de estar localizada num bairro pobre da cidade justifica o descaso e é reflexo da discriminação com a população mais pobre (Relatório narrativo da visita à delegacia A10, em Recife).

Logo, uma grande contribuição da pesquisa para os estudos sobre o funcionamento das organizações policiais é a de apresentar o imaginário que os cidadãos possuem acerca das delegacias e como esse muda (ou não) com a participação na Semana de Visitas. Com isso, pode-se, além de avaliar a própria polícia, viabilizar a desmistificação de quem são os policiais e o oferecimento de subsídios para a elaboração de políticas públicas que permitam a aproximação entre polícia e comunidade.

\section{Os dados da Semana de Visitas a Delegacias de Polícia e o Conceito de Direitos Humanos: duas faces de uma mesma moeda?}

Como já destacado anteriormente, os dados coletados no âmbito da Semana de Visitas são resultados de observações diretas de potenciais usuários dos serviços no que diz respeito aos seguintes itens: 


\section{ARTIGOS}

orientação para a comunidade; condições materiais; tratamento igualitário do público; transparência e prestação de contas; e condições de detenção. Assim, considerando a média de pontos recebida por cada delegacia, é possível classificar o atendimento oferecido por essa agência à população em categorias que variam desde totalmente inadequada até excelente (Tabela 1 ).

Tabela 1 - Intervalos de pontuação para classificação da qualidade do atendimento prestado pelas delegacias de polícia - Altus, 2009

\begin{tabular}{c|c}
\hline Intervalo de pontos & Categoria \\
\hline $20-35$ pontos & Totalmente inadequado \\
\hline $36-51$ pontos & Inadequado \\
\hline $52-67$ pontos & Adequado \\
\hline $68-84$ pontos & Mais do que adequado \\
\hline 85-100 pontos & Excelente \\
\hline \multicolumn{2}{c}{ Fonte: Altus (2010, p. 19$).$}
\end{tabular}

Para o ano de 2009, com o uso dessa metodologia, foi possível constatar que, em média, as delegacias visitadas no Brasil prestam um serviço que, na perspectiva do próprio usuário, é inadequado (Tabela $\left.2^{13}\right)$.

\footnotetext{
13 As tabelas foram construídas a partir das bases de dados da Altus, que não foram publicizadas com o propósito de se garantir que as delegacias com piores notas/condições não sejam expostas a constrangimentos públicos.
} 
Tabela 02 - Média de pontos Avaliação da qualidade do atendimento prestado pelas delegacias de polícia, por região -

III Semana de Visitas a Delegacias de Polícia - 2009

\begin{tabular}{c|c|c|c|c|c|c}
\hline Cidade & $\begin{array}{c}\text { Avaliação } \\
\text { geral }\end{array}$ & $\begin{array}{c}\text { Orientação } \\
\text { para a } \\
\text { comunidade }\end{array}$ & $\begin{array}{c}\text { Condições } \\
\text { materiais }\end{array}$ & $\begin{array}{c}\text { Tratamento } \\
\text { igualitário }\end{array}$ & $\begin{array}{c}\text { Transparência } \\
\text { e prestação de } \\
\text { contas }\end{array}$ & $\begin{array}{c}\text { Condições } \\
\text { de } \\
\text { detenção }{ }^{14}\end{array}$ \\
\hline Brasília & 56 & 64 & 67 & 63 & 40 & 46 \\
\hline $\begin{array}{c}\text { Rio de } \\
\text { Janeiro }\end{array}$ & 53 & 62 & 60 & 55 & 42 & 45 \\
\hline São Paulo & 52 & 61 & 66 & 52 & 37 & 44 \\
\hline $\begin{array}{c}\text { Belo } \\
\text { Horizonte }\end{array}$ & 49 & 60 & 61 & 50 & 35 & 38 \\
\hline Pelotas/RS & 48 & 64 & 65 & 47 & 40 & 23 \\
\hline Brasil & 47 & 57 & 57 & 47 & 37 & 39 \\
\hline Porto Alegre & 45 & 55 & 53 & 40 & 37 & 39 \\
\hline Fortaleza & 43 & 51 & 51 & 43 & 35 & 35 \\
\hline Goiânia & 41 & 50 & 50 & 39 & 33 & 33 \\
\hline Recife & 39 & 48 & 48 & 36 & 31 & 32 \\
\hline Belém do & 39 & 47 & 50 & 36 & 33 & 27 \\
\hline Pará & 36 & 49 & 40 & 31 & 26 & 35 \\
\hline Juruti/PA & 36 & & & &
\end{tabular}

Se em algumas localidades, como Brasília, Rio de Janeiro e São Paulo, as delegacias possuem um atendimento classificado como adequado, isso não ocorre no restante das localidades analisadas. Os casos mais preocupantes são Recife, Belém do Pará e Juriti (PA), localidades nas quais a média das delegacias é muito próxima do valor que as classificaria como totalmente inadequadas.

Os grupos de visitantes, por sua vez, foram estruturados de maneira a garantir que a diversidade em termos de idade, sexo, orientação sexual, classe social, escolaridade, raça/cor e ter ido ou não a uma delegacia de polícia. Esses critérios eram importantes para se garantir que as notas finais das delegacias não fossem enviesadas pelo perfil dos participantes, ou seja, dos avaliadores.

Realizando os cálculos necessários para afastar essa hipótese, foi possível perceber que a avaliação geral dos serviços comumente prestados pelas delegacias de polícia é negativa independente de quem

\footnotetext{
14 Nesse critério, é importante destacar as diferenças entre os estados brasileiros em relação às funções das delegacias, já que em alguns casos as delegacias não são utilizadas como espaço de detenção, não possuindo carceragem, algo que, impactaria, portanto, a avaliação do último quesito. Com o intuito de evitarmos problemas dessa natureza, nos estados que não possuem delegacias com carceragem, o que é avaliado é a capacidade da unidade em realizar uma custódia segura, do ponto de vista dos policiais e dos cidadãos e em consonância com os direitos fundamentais do detido. Essa estratégia metodológica será esclarecida em detalhes na parte desta seção que trata das condições de detenção.
} 
avalia, tanto em termos de sexo (Tabela 03), como em termos de idade (Tabela 04), como em termos de grau de escolaridade (Tabela 05).

Tabela 03 - Média de pontos da avaliação da qualidade do atendimento prestado pelas delegacias de polícia, por sexo do visitante -

III Semana de Visitas a Delegacias de Polícia - 2009

\begin{tabular}{c|c|c|c|c|c}
\hline Sexo & Número de casos & Mínimo & Máximo & Média & Desvio Padrão \\
\hline Feminino & 658 & 20 & 100 & 47 & 15 \\
\hline Masculino & 506 & 20 & 98 & 48 & 14 \\
\hline Total & 1.164 & 20 & 100 & 47 & 15 \\
\hline
\end{tabular}

Tabela 04 - Média de pontos da avaliação da qualidade do atendimento prestado pelas delegacias de polícia, por idade do visitante -

III Semana de Visitas a Delegacias de Polícia - 2009

\begin{tabular}{c|c|c|c|c|c}
\hline Idade em faixas & $\begin{array}{c}\text { Número de } \\
\text { casos }\end{array}$ & Mínimo & Máximo & Média & Desvio Padrão \\
\hline Até 20 anos & 505 & 21 & 96 & 48 & 14 \\
\hline Entre 21 e 30 anos & 299 & 20 & 98 & 46 & 15 \\
\hline Entre 31 e 40 anos & 162 & 20 & 100 & 47 & 15 \\
\hline Entre 41 e 50 anos & 98 & 21 & 100 & 46 & 16 \\
\hline Entre 51 e 60 anos & 74 & 20 & 76 & 47 & 14 \\
\hline Acima de 61 anos & 22 & 24 & 75 & 48 & 14 \\
\hline Total & 1.160 & 20 & 100 & 47 & 15 \\
\hline
\end{tabular}

Tabela 05 - Média de pontos da avaliação da qualidade do atendimento prestado pelas delegacias de polícia, por grau de escolaridade do visitante III Semana de Visitas a Delegacias de Polícia - 2009

\begin{tabular}{c|c|c|c|c|c}
\hline $\begin{array}{c}\text { Grau de escolaridade } \\
\text { Curso Fundamental } \\
\text { incompleto }\end{array}$ & $\begin{array}{c}\text { Número } \\
\text { de casos }\end{array}$ & Mínimo & Máximo & Média & $\begin{array}{c}\text { Desvio } \\
\text { Padrão }\end{array}$ \\
\hline Curso Fundamental & 28 & 26 & 87 & 50 & 16 \\
\hline Curso Médio incompleto & 56 & 22 & 82 & 46 & 15 \\
\hline Curso Médio & 199 & 20 & 93 & 47 & 15 \\
\hline Curso Técnico incompleto & 6 & 31 & 52 & 41 & 14 \\
\hline Curso Técnico & 12 & 31 & 66 & 51 & 10 \\
\hline Curso Superior incompleto & 451 & 21 & 100 & 48 & 15 \\
\hline Curso Superior & 374 & 20 & 100 & 47 & 15 \\
\hline Total & 1.164 & 20 & 100 & 47 & 15 \\
\hline
\end{tabular}

A avaliação da qualidade do atendimento prestado pelas delegacias de polícia em todo Brasil também não difere de acordo com a experiência anterior que o visitante possui com o projeto (Tabela 06), com o número de vezes em que ele tinha estado em uma delegacia de polícia (Tabela 07) e com o fato de ele, ou qualquer pessoa de sua família, ter sido vítima de um crime nos últimos doze meses (Tabela 08). 
Tabela 06 - Média de pontos da avaliação da qualidade do atendimento prestado pelas delegacias de polícia, por experiência anterior do visitante com o projeto - III Semana de Visitas a Delegacias de Polícia - 2009

\begin{tabular}{c|c|c|c|c|c}
\hline $\begin{array}{c}\text { Já participou das edições } \\
\text { anteriores da semana de } \\
\text { visitas? }\end{array}$ & $\begin{array}{c}\text { Número } \\
\text { de } \\
\text { casos }\end{array}$ & Mínimo & Máximo & Média & $\begin{array}{c}\text { Desvio } \\
\text { Padrão }\end{array}$ \\
\hline Não & 1.118 & 20 & 100 & 47 & 15 \\
\hline Sim & 46 & 20 & 98 & 50 & 16 \\
\hline Total & 1.164 & 20 & 100 & 47 & 15 \\
\hline
\end{tabular}

Tabela 07 - Média de pontos da avaliação da qualidade do atendimento prestado pelas delegacias de polícia, por número de vezes que o visitante já esteve em uma delegacia de polícia -

III Semana de Visitas a Delegacias de Polícia - 2009

\begin{tabular}{c|c|c|c|c|c}
\hline $\begin{array}{c}\text { Número de vezes que já } \\
\text { esteve em uma delegacia } \\
\text { com exceção dessa visita }\end{array}$ & $\begin{array}{c}\text { Número de } \\
\text { casos }\end{array}$ & Mínimo & Máximo & Média & $\begin{array}{c}\text { Desvio } \\
\text { Padrão }\end{array}$ \\
\hline Nenhuma & 271 & 20 & 92 & 47 & 13 \\
\hline Uma vez & 176 & 21 & 98 & 48 & 15 \\
\hline Duas vezes & 222 & 21 & 100 & 48 & 16 \\
\hline Três vezes & 144 & 20 & 88 & 47 & 16 \\
\hline Quatro vezes & 93 & 22 & 96 & 46 & 15 \\
\hline Cinco vezes & 58 & 26 & 98 & 47 & 15 \\
\hline Seis vezes & 200 & 20 & 100 & 47 & 15 \\
\hline Total & 1.164 & 20 & 100 & 47 & 15 \\
\hline
\end{tabular}

Tabela 08 - Média de pontos da avaliação da qualidade do atendimento prestado pelas delegacias de polícia, por vitimização do visitante ou de alguém da sua família nos últimos doze meses -

III Semana de Visitas a Delegacias de Polícia - 2009

\begin{tabular}{c|c|c|c|c|c}
\hline $\begin{array}{c}\text { Você, ou alguém da sua } \\
\text { família, foi vítima de um } \\
\text { crime nos últimos doze } \\
\text { meses? }\end{array}$ & $\begin{array}{c}\text { Número de } \\
\text { casos }\end{array}$ & Mínimo & Máximo & Média & $\begin{array}{c}\text { Desvio } \\
\text { Padrão }\end{array}$ \\
\hline Não & 728 & 20 & 98 & 48 & 15 \\
\hline Sim & 436 & 20 & 100 & 47 & 15 \\
\hline Total & 1.164 & 20 & 100 & 47 & 15 \\
\hline
\end{tabular}

Ou seja, independe do perfil que o visitante possui (em termos de sexo, idade, grau de escolaridade, experiência anterior na pesquisa, interação pretérita com a polícia, vitimização parental no último ano), ele avalia a qualidade do serviço prestado pelas delegacias de polícia brasileiras como inadequada, algo que reforça a validade dos dados coletados no âmbito da Semana de Visitas a Delegacias de Polícia do ponto de vista de sua cientificidade.

Contudo, considerando que esses indivíduos, com perfis os mais distintos possíveis, permaneceram pelo menos uma hora e meia em uma delegacia de polícia para avaliarem-na, é possível dizer que os 
participantes puderam pensar no papel desempenhado pela polícia e, ainda, nas limitações que esta organização possui para o desempenho do seu trabalho. Neste sentido, talvez a maior contribuição da pesquisa para os estudos dessa natureza seja a de apresentar o imaginário que os cidadãos possuem acerca da organização policial.

Logo, mais do que as notas dadas às 20 perguntas que compõem o questionário da pesquisa, as impressões dos visitantes acerca do funcionamento, da rotina de uma delegacia nas cinco dimensões avaliadas, medidas por meio de uma conversa entre o grupo e, posteriormente, traduzida em relatório narrativo, são de extrema importância para o entendimento da consonância existente entre as práticas dos policiais civis e direitos humanos.

Para vários visitantes, muitas delegacias têm que melhorar o atendimento ao público, em termos de acessibilidade à própria delegacia, serviços, informações e equipe de atendimento dos cidadãos que chegam para registrar ocorrências ou em busca de informações.

O grupo avaliou inadequadas as condições da delegacia quanto à acessibilidade, faltam elevadores e rampas. Não há informações disponíveis sobre como registrar queixas e/ou obter serviços públicos; e os funcionários não estavam devidamente identificados. Existe um Banner na recepção indicando os serviços que a delegacia presta, alguns destes não existem como a brinquedoteca e auditório, estes são usados como depósito de apreensões. O banheiro para o público é único com separação de sexo interno. Possui uma sala grande de espera com um balcão para o primeiro atendimento, no momento sem funcionários e outro balcão para atendimento propriamente dito, não havia salas separadas para atendimento individual de casos delicados. Os usuários reclamaram da demora no atendimento (Relatório narrativo da visita à delegacia A87, em São Paulo).

Por outro lado, algumas delegacias têm se destacado no que concerne à orientação da comunidade, procurando ser mais acessíveis e receptivas.

Os visitantes se surpreenderam com a excelente recepção que tivemos e com o grau de organização e 
envolvimento apresentado. Da mesma forma, a capacidade de precisar atividades e trabalhar coordenadamente, pareceu-nos se tratar de uma delegacia com padrão de atendimento diferenciado. Da mesma forma, não só a preocupação e sensibilidade para a especificidade de suas atividades nos surpreendeu, como a percepção de que não é atribuição da polícia julgar as vítimas pelos crimes sofridos, buscando-se soluções de apoio a vítimas e agressores que ultrapassem o âmbito estritamente policial ou punitivo, como alcoólicos anônimos e apoio psicológico para vítimas e infratores (Relatório narrativo da visita à delegacia A186, em Brasília).

Os visitantes destacaram ainda que as sedes possuem boas instalações e equipamentos em estado razoável de conservação, fatores estes que são importantes para o adequado desempenho do trabalho policial.

O excelente estado de conservação do prédio e das condições de trabalhos dos agentes daquela unidade fez reanimar a confiança dos integrantes do grupo num bom trabalho que pode ser realizado pela policia (Relatório narrativo da visita à delegacia A9, em Recife).

O prédio está na medida possível em bom estado de conservação, a limpeza bem adequada, como cestos de lixos bem distribuídos. O local onde o público costuma esperar para fazer os boletins de ocorrência, no meu ponto de vista e o das demais visitantes era apropriado, com assentos confortáveis e um bebedouro próximo. Tivemos a oportunidade de conversar com um casal que esperava para ser atendido, eles nos disseram que 0 atendimento costuma ser rápido (Relatório narrativo da visita à delegacia A142, em São Paulo).

No entanto, outros visitantes constataram que várias delegacias ainda se encaixam no estereótipo de repartições sujas, desorganizadas e, por isso, hostis ao público.

Nesta delegacia ficou claro o quanto é o descaso em atender a comunidade do bairro. Pois o prédio não supre as necessidades básicas para o atendimento da mesma (Relatório narrativo da visita à delegacia A21, em Belém do Pará). 
O estado de conservação do prédio é precário, com alguns pedaços do piso destruído, paredes sujas e com pinturas antigas, sem limpeza freqüente e com mobílias, computadores e telefones antigos, defasados e com defeitos freqüentes, o que atrapalha muito alguns atendimentos. Esta é também a leitura feita pelos próprios funcionários, inclusive do delegado. A escrivã que nos atendeu relatou que muitas vezes demora mais de duas horas pra registrar um boletim de ocorrência devido à lentidão do sistema de informática utilizado. Todos os funcionários queixaram-se dessa condição e disseram-se pessimistas com a classificação na pesquisa. A impressão que nos deu é de que a delegacia não possui condições físicas de prestar um bom atendimento, onde o conforto e uma boa sensação não estão presentes (Relatório narrativo da visita à delegacia A13, em Goiânia).

No que tange ao tratamento igualitário do público, sem preconceito de gênero, etnia, nacionalidade, idade ou orientação sexual, na maioria das delegacias, o público notou a ausência de informações, serviços e encaminhamentos para pessoas ou grupos em condições vulneráveis tais como crianças, mulheres, homossexuais, deficientes físicos e idosos.

Possui equipe para registrar termos de ocorrência e orientação ao público. Há um espaço exclusivo para os boletins de ocorrência, mas não há serviços de apoio e atendimento para grupos específicos como mulheres e homossexuais (Relatório narrativo da visita à delegacia A9, em Recife).

Não há nenhum atendimento específico para mulheres, idosos ou deficientes, nem atendimento médico. Casos desse tipo são encaminhados para delegacias especiais ou hospitais, através da viatura da Polícia Civil (Relatório narrativo da visita à delegacia A73, em Belo Horizonte).

Da mesma forma, foi observado que várias delegacias não possuem espaços específicos para entrevistar vítimas ou testemunhas de crimes, nos casos em que a privacidade é importante.

Outro fator que contribuiu para uma impressão pouco positiva foi 0 fato das salas serem separadas por divisórias e não paredes, deixando o som acessível, conferindo pouca privacidade a vítimas e testemunhas 
(Relatório narrativo da visita à delegacia $\mathrm{A} 104$, em São Paulo).

Em outras situações, apesar de a delegacia ser equipada com tais espaços, os policiais continuam a agir como se esses não existissem. Ou seja, mais importante do que as condições materiais para realizar um bom atendimento da população, é o entendimento dos policiais de que o uso de tais equipamentos é indispensável para a garantia dos direitos humanos de todos aqueles que procuram as unidades.

A delegacia possui um local destinado ao atendimento do público com: balcão de atendimento, bancos de espera, bebedor de água, banheiros masculino e feminino, e uma televisão. No entanto, o balcão para registrar os boletins de ocorrência não possui divisões e quando as pessoas estão registrando suas queixas, podem ser ouvidas pelas demais. O Delegado relatou que para os atendimentos de crimes, na qual a privacidade é importante, as pessoas são encaminhadas ao segundo andar da delegacia em uma sala reservada e normalmente uma atendente mulher é destinada ao atendimento. Quando estávamos no segundo andar da delegacia, tentamos conversar com uma senhora que estava esperando para falar com o Delegado desde que havíamos chegado na delegacia. No momento em que a abordamos, o Delegado interveio e a atendeu rapidamente no meio do corredor, sendo que, 0 caso se tratava de um assunto relacionado à violência doméstica. Como o Delegado estava com pressa, porque estava nos acompanhando na visita, ele passou o caso para um investigador. Os visitadores relataram que se sentiram indignados com a atitude do delegado ao atender esta senhora, primeiro por se tratar de um tema delicado que foi exposto no meio do corredor, e segundo porque ele só prestou atendimento a esta senhora, porque nós fomos conversar com ela (Relatório narrativo da visita à delegacia A90, em Belo Horizonte).

Havia uma sala destinada a identificação de testemunhas com vidro escuro que não permitia que a pessoa do outro lado fosse vista. Porém, na frente do vidro, fora colocado um armário grande e alto que também impediria a identificação do suspeito, pois ele tapava completamente a "janela" (Relatório narrativo da visita à delegacia A120, no Rio de Janeiro).

Outras realidades diferem substancialmente desta, pois apesar das limitações em termos de infra-estrutura física, diversos delegados 


\section{ARTIGOS}

têm se preocupado em administrar o problema e, desta forma, garantir a privacidade dos envolvidos.

Também não havia espaços adequados para o registro de ocorrências, que é feito no balcão da recepção. Quando há necessidade de conversa com vítimas especiais ou que precisem de privacidade, este serviço é feito em uma pequena sala, sem ventilação, próxima à cozinha e aos banheiros (Relatório narrativo da visita à delegacia A70, em Belo Horizonte).

A Delegacia possuía todos os serviços que são estabelecidos pelo comando geral. Porém me chamou atenção a seção de atendimento à mulher. Lá trabalhavam apenas um homem e uma mulher. $O$ delegado nos informou que em casos que a mulher precisa de "privacidade" o homem costumava se retirar para que a mulher pudesse relatar o seu caso com mais privacidade (Relatório narrativo da visita à delegacia A184, em Brasília).

O item transparência e prestação de contas foi aquele em que os visitantes demonstraram maiores críticas. Os problemas neste quesito começam logo na entrada da delegacia: poucos são os exemplos de policiais uniformizados, fazendo com que a principal dificuldade do usuário seja identificar quem é o policial.

Os policiais, os dois policiais que estiveram na delegacia enquanto realizamos nossa visita, não poderiam ser identificados. Só era possível ter a noção de que eram policiais a partir do local em que estavam trabalhando. Nada mais os distinguira de uma pessoa que estivesse apenas de passagem pela delegacia. E se fosse se basear na vestimenta que identifica os trabalhadores da delegacia, uma pessoa seria levada ao equívoco acreditando que os dois "funcionários" aparentemente vestidos como policiais, como já foi dito, eram apenas prestadores de serviço para a delegacia. Fora isto, não existia nenhum crachá, etiqueta ou qualquer outra forma de identificar as pessoas com as quais se interagiam (Relatório narrativo da visita à delegacia A120, no Rio de Janeiro).

Ao entrarmos na delegacia havia um bom movimento já que algumas pessoas estavam sendo atendidas. Os policiais estavam atendendo várias pessoas e nós tivemos dificuldade de identificar quem eram os policiais e quem eram os civis já que aqueles não tinham nenhuma identificação como crachá ou uniforme 
- apenas posteriormente vimos que havia uma mulher com uma camisa da Polícia Civil, porém esta não estava na recepção quando chegamos. Neste momento ocorreu um fato curioso: quando me aproximei da mesa de recepção e logo percebi quem poderia ser um possível policial me identifiquei a ele e perguntei sobre quem poderia nos receber. Eles estavam atendendo muitas pessoas ao mesmo tempo e tivemos que esperar algum tempo. Mas neste primeiro momento em que abordei o policial e conversamos sobre quem poderia nos atender, entra na delegacia um homem de terno, que parecia ser um advogado, e me pede uma informação, como se eu fosse um policial, justamente porque não havia uma identificação clara e em torno de toda aquela mistura entre policiais e civis, tudo ficou ainda mais confuso (Relatório narrativo da visita à delegacia A228, em Belo Horizonte).

Não raro, percebe-se a inexistência de informativos em relação às reclamações que o público possa ter para fazer sobre a delegacia. De acordo com os visitantes, caso o público questione acerca da existência de tal órgão, os policiais encaminham para o delegado as queixas ou pedem para ligar direto para algum número.

A prática de encaminhar as reclamações para o próprio delegado parece ser utilizada como estratégia de corporativismo, no sentido de que alguns gestores a manipulam com o intuito de fazer com que os maus policiais não sejam punidos. Aliás, neste ponto, as percepções dos visitantes são extremamente críticas quanto à discrepância entre os discursos dos policiais e o que é verificado na realidade cotidiana das delegacias de polícia.

O discurso do delegado soou estranho, voltado para nos convencer sobre sua dedicação, a qualidade de seu trabalho e índole moral. Algumas cenas mostraram o contrário, como, por exemplo, a omissão dele diante de um investigador que destratou um rapaz em averiguação na delegacia na frente da equipe de visitas, ou a falta de cartazes sobre ouvidoria ou corregedoria acompanhada do discurso do delegado de que isso é desnecessário, pois se alguém tiver reclamação a fazer, tem de ter coragem para falar com ele (Relatório narrativo da visita à delegacia A88, em São Paulo).

Outro problema identificado foi o relacionado à publicidade do 
que a polícia faz. A dificuldade não parece ser produzir informação sobre número de crimes, inquéritos e criminosos na região, mas em construir uma visão de que esta é de interesse público. Os policiais temem esta publicidade especialmente pelo que ela poderia implicar em termos de cobrança da comunidade por maior efetividade, por exemplo, no esclarecimento de delitos. Daí porque eles elaboram discursos os mais variados possíveis para se eximirem desta responsabilidade.

Os policiais argumentam que um mapa criminal facilitará a informação dos criminosos e irá alardear a população inutilmente. Mas o argumento é frágil, uma vez que não possibilita à população qualquer tipo de informação sobre crimes cometidos e/ou orientações sobre como se comportar diante de algum tipo de delito. Além disso, a delegacia não apresenta informativos quanto ao número de casos solucionados, inquéritos concluídos ou afim. É importante ressaltar que há resistência dos policiais nesse tipo de esclarecimento à população (Relatório narrativo da visita à delegacia A124, no Rio de Janeiro).

Mais interessante ainda parece ser o fato de algumas delegacias justificarem o segredo de tais informações e, ainda, a não identificação dos policiais como uma prática que tem por objetivo garantir a segurança da própria população usuária deste serviço.

O distrito policial conta com um mapa de sua circunscrição no saguão de atendimento. No entanto, não conta com qualquer informação a respeito de: tendências de crime na região; desempenho e trabalho da delegacia; e, informações de como relatar desvios de conduta da equipe policial. O delegado relatou que não pode expor na delegacia, os dados sobre os locais de crime na região porque: primeiro, o público não ia mudar os seus hábitos cotidianos; segundo, seria contra produtivo, uma vez que, os criminosos teriam acesso a esta informação e saberiam onde não agir; terceiro, os comerciantes se sentiriam prejudicados, pois caso o público mudasse os seus hábitos, ele poderia deixar de consumir em determinados locais. Cabe destaque que os funcionários da delegacia não estavam uniformizados e não estavam identificados. O delegado disse que os funcionários não utilizavam o "cagueta", por motivos de segurança (Relatório narrativo da visita à delegacia A145, em São Paulo). 
Para além dos problemas encontrados, algumas delegacias se destacaram por cumprir minimamente o previsto nos diversos diplomas legais que regulamentam esta questão. Principalmente nas Especializadas de Atendimento à Mulher, há cartazes sobre serviços públicos, orientações sobre os direitos individuais, números de outros órgãos, inclusive da Ouvidoria de Polícia.

Por todo lado há cartazes sobre serviços públicos, orientações sobre os direitos da mulher, números de outros órgãos, inclusive da Ouvidoria de Polícia (Relatório narrativo da visita à delegacia A177, no Rio de Janeiro).

Há também uma televisão e também cartazes informando sobre outros serviços, como por exemplo, um papel afixado com dados sobre o número de ocorrências registradas no mês de outubro e como os endereços e telefones da Corregedoria e Ouvidoria da Policia Civil e da Vara da Infância e do Adolescente. Apesar dos dados disponíveis, não havia explicações sobre o que são tais instituições e como registrar queixas de desvios de conduta da equipe da delegacia. $\mathrm{O}$ delegado coloca à disposição das vítimas femininas uma funcionária para dar encaminhamento às demandas que aparecem e uma sala especial. O mesmo disse que faz primeiro 0 atendimento na delegacia e logo após encaminha para a Delegacia da Mulher. Dependendo do caso, chega a disponibilizar um carro para levar a mulher, devido à longa distância da sede da delegacia da Mulher (Relatório narrativo da visita à delegacia A157, em São Paulo).

Um último item avaliado diz respeito às condições de detenção. Em regra, as delegacias deveriam contar com espaços para a permanência dos suspeitos apenas durante os procedimentos da prisão em flagrante e, para isso, não são necessárias unidades de detenção propriamente dita. Na perspectiva de Soares (2000, p. 90), "as delegacias com carceragem constituem uma ilegalidade com a qual tanto os cidadãos como os policiais brasileiros se acostumaram e, apesar das ilegalidades que são prementes nessa seara, poucas são as ações empreendidas com o sentido de reverter tal cenário".

Essa dualidade de entendimentos a respeito da funcionalidade da presença (ou ausência) de carceragens faz com que nesse item sejam 
avaliadas não apenas as condições da detenção, mas também as condições da custódia. Esse detalhe é importante porque, em diversas localidades, sob o argumento de que não possuem carceragem nas delegacias, os policiais mantêm os detentos algemados em corrimões ou sofás por horas, conduta essa que se opõe diretamente ao conceito de direitos humanos.

A delegacia não possui carceragem. Os presos em flagrante permanecem algemados a uma barra de ferro em um banco de concreto até que todo o procedimento seja feito. Essa estrutura está localizada no corredor da delegacia (Relatório narrativo da visita à delegacia A14, em Goiânia).

A "carceragem" é um banco antigo e com o assento todo desgastado, onde os detentos são algemados. O banco - que não é preso no chão e é extremamente leve - fica no meio de um corredor estreito onde as pessoas passam o tempo todo. A escada que leva aos escrivães e à sala da delegada fica na frente do banco dos detentos (Relatório narrativo da visita à delegacia A73, em Belo Horizonte).

Os capturados sob suspeita de crime ficavam temporariamente numa sala algemados sob uma barra de ferro até a viatura levá-los para outras Delegacias (Relatório narrativo da visita à delegacia A137, em Fortaleza).

Nas delegacias que possuem carceragem, o cenário é ainda pior e mais desrespeitoso em relação aos direitos humanos do acusado. Tanto é assim que diversos coordenadores de visita fizeram alusões a jaulas ao descreverem esse espaço e suas condições. Importante destacar que, em flagrante ilegalidade, em algumas situações, esses espaços funcionam como prisões.

Entrando na carceragem é impossível ficar sem prender a respiração, o forte cheiro que vem das latrinas, paredes riscadas por fezes e por folhas que caem pela pequena entrada do teto para a luz, quente, chão de concreto batido e bastante poeira (Relatório narrativo da visita à delegacia $A 7$, em Recife).

Com relação às condições de detenção, verificou-se superlotação na área destinada para fim de detenção, as grades estavam sendo reconstituídas, remendadas 
depois de tantas investidas por parte dos detentos de invasão e na tentativa de fuga as janelas receberam uma chapa de ferro, o que impossibilitou a circulação de ar no espaço (Relatório narrativo da visita à delegacia A20, em Belém do Pará).

Os presos são mantidos em uma pequena cela, que mais parece uma jaula, no mesmo ambiente onde são registradas as ocorrências. O espaço é apertado, pouco iluminado e apesar de ter três cadeados, não parece muito seguro. Não há banheiro específico nem local para visitas (Relatório narrativo da visita à delegacia A227, em Belo Horizonte).

A Delegacia dispõe de uma cela para confinamento temporário de presos, essa apesar de estar em boas condições de segurança, é um local escuro, pichado e sem condições higiênicas (Relatório narrativo da visita à delegacia A211, em Porto Alegre).

A descrição dos cincos itens avaliados parece evidenciar, portanto, que os dados coletados pela Semana de Visitas podem e devem ser utilizados para a melhor compreensão de como os policiais, de distintas localidades, operacionalizam o seu trabalho e, com isso, garantem uma maior ou menor efetividade dos direitos humanos, se não de toda uma população, de uma dada parcela desta.

Contudo, essas práticas diferenciadas nada mais fazem do que reforçarem as desigualdades existentes na sociedade brasileira. Afinal, tal como destacado por Manning (2009), a polícia apenas reflete o que a sociedade espera dessa organização. Assim, se essa agência continua a operar de maneira pouco orientada para a comunidade como um todo, tratando desigualmente os indivíduos em razão de seu sexo, raça, idade e orientação sexual, é porque, em última instância, é isso que se espera dela. Deste modo, as delegacias de polícia no Brasil parecem estar institucionalizando com propriedade a prática de se tratar desigualmente os desiguais (tal como destacado nos trabalhos de Kant de Lima, 1989 e 2004) e, aliás, quando não o fazem tal como socialmente esperado, causam estranheza em seus usuários.

Já esperávamos uma delegacia em piores condições, dada a região que está instalada (Relatório narrativo da visita à delegacia A128, em Belo Horizonte). 
Pensávamos que as condições físicas seriam melhores por estar em um bairro nobre da cidade (Relatório narrativo da visita à delegacia A224, em Brasília).

A delegacia causou uma ótima impressão. Talvez por se tratar de uma região empobrecida do município de São Paulo, não se esperava uma delegacia com condições tão adequadas de atendimento e tão bonita e organizada (Relatório narrativo da visita à delegacia A100, em São Paulo).

Portanto, os dados coletados no âmbito da Semana de Visitas indicam que o maior problema identificado pelos cidadãos brasileiros nas delegacias de polícia parece ser o relacionado à ausência de preocupação com a transparência e prestação de contas. As dificuldades começam logo ao adentrar pela delegacia, já que como os policiais não estão uniformizados ou identificados é difícil saber quem é a polícia ou o criminoso ou a vítima do delito.

As percepções dos visitantes parecem apontar ainda para um segundo problema: as condições de detenção. Em diversos estados, as delegacias de polícia contam com carceragens cujas condições estão longe de materializar o idealizado pelos tratados de direitos humanos. A situação não é distinta nas delegacias sem carceragens, que devem lidar com o indivíduo preso em flagrante, este permanecendo na unidade, pelo menos, até a finalização do registro da ocorrência. Não são raros os casos de indivíduos presos nestas circunstâncias que permanecem algemados a corrimões de delegacias, devendo fazer ali mesmo as suas necessidades fisiológicas.

Por outro lado, as delegacias do Brasil foram avaliadas como adequadas no que se refere aos critérios orientação para a comunidade e condições materiais e, em diversas situações, os visitantes destacaram a sua surpresa em relação a esse cenário:

As impressões que eu, como coordenador das visitantes, em conjunto com os visitantes foi que o trabalho realizado na delegacia é de boa qualidade. Apesar de diversas incorrespondências que ocorreram em relação ao formulário, onde muitos itens acabaram sendo mal avaliados e com eventuais problemas que de 
fato ocorrem na delegacia o que sobressaiu para toda a equipe é que, se considerando as condições oferecidas aos policiais e ao delegado, ali há um bom trabalho. Assim, se considerado o contexto do Brasil e de Belo Horizonte, levando-se em conta o que é oferecido à delegacia e as limitações que ela enfrenta a impressão de todo o grupo foi que a delegacia presta um bom serviço à comunidade (Relatório narrativo da visita à delegacia A225, em Belo Horizonte).

Paralelamente, os dados parecem indicar ainda que o estereótipo comumente construído sobre a polícia está muito distante do igualitarismo pretendido pelo atual conceito de direitos humanos ${ }^{15}$ : uma delegacia onde se pede para entrar, uma delegacia que acorrenta os elementos suspeitos de cor padrão ao corrimão, mas que recebe bem os pesquisadores de uma agência internacional, uma delegacia que possui condições para atendimento igualitário, mas que continua a empreender um tratamento diferenciado de acordo com as características do usuário são exemplos típicos da distância existente entre o conceito de direitos humanos e a prática dos operadores do direito.

\section{Considerações finais}

A proposta desse artigo foi discutir a relação entre direitos humanos e práticas policiais a partir das percepções de cidadãos sobre 235 delegacias de polícia no Brasil. Esse tema é importante porque, de acordo com as pesquisas no Brasil, existe um grande vazio de confiança nas unidades policiais porque, na maioria das vezes, o trabalho realizado por estas ocorre em total desrespeito aos direitos humanos.

A Semana de Visitas foi escolhida como base de dados para essa análise por reunir percepções dos indivíduos acerca de como as delegacias de polícia se configuram em termos de orientação para a comunidade, condições materiais, tratamento igualitário do público, transparência e prestação de contas, e condições de detenção.

Conectando as informações dessa pesquisa com a interpretação contemporânea de direitos humanos enquanto mecanismos capazes de prover tratamento igual aos diferentes, universalizando a aplicação da

15 Tal como constatado anteriormente por Nascimento (2003). 
lei às distintas identidades que se especificam no espaço público, é possível afirmar que, na percepção dos visitantes, os policiais civis ainda atuam muito mais como operadores de direitos diferenciados do que de direitos iguais para todos.

Especialmente quando se constata que as deficiências dessas delegacias parecem se concentrar especialmente nas searas transparência e prestação de contas e condições de detenção parece evidente que alguns têm mais acesso a um tratamento de acordo com as regras constitucionais. Outros, em razão de seu perfil ou do fato de suas características se coadunarem com as de um indivíduo que deve ser incriminado, devem ser tratados de maneira diferenciada. Assim, a polícia termina por realizar o que a sociedade espera, já que de acordo com os próprios visitantes, deve-se esperar que as delegacias melhores (em termos materiais e operacionais) estejam situadas nas áreas nobres da cidade, enquanto o restante da população deve se conformar com delegacias pouco equipadas e pouco preparadas para acolher o cidadão que a elas se dirige procurando atendimento.

Não é por acaso que a autoridade de que um projeto internacional desfruta garante a abertura das delegacias para a pesquisa; também não é acidente que as condições gerais das delegacias sejam piores nos estados mais pobres da federação do que nos mais ricos (ver Tabela 02) e também não é coincidência que o item transparência e prestação de contas, que garantiria a universalidade de informação e acessibilidade a todas as delegacias, seja aquele no qual estas possuem as notas mais baixas. São exatamente essas dimensões que garantem a relativização do universalismo pretendido pelos direitos humanos diante da situação concreta.

Ludmila Mendonça Lopes Ribeiro é doutora em Sociologia pelo Instituto Universitário de Pesquisas do Rio de Janeiro (IUPERJ) e pesquisadora do Centro de Pesquisa e Documentação de História Contemporânea do Brasil (CPDOC), da Fundação Getúlio Vargas (FGV). Em 2009, foi coordenadora nacional da Semana de Visitas a Delegacias de Polícia no Brasil.

E-mail: ludmila.ribeiro@gmail.com 
Klarissa Almeida Silva é doutoranda em Sociologia pelo Programa de Pós-Graduação em Sociologia e Antropologia da UFRJ e pesquisadora do Núcleo de Estudos da Cidadania, Conflito e Violência Urbana (NECVUUFRJ). Em 2009, foi coordenadora regional da Semana de Visitas a Delegacias de Polícia no Rio de Janeiro.

E-mail: silva.klarissa@gmail.com

\section{Referências:}

ALTUS. Documentos Administrativos da Altus. Rio de Janeiro: Altus, 2006.

III Semana de Visitas a Delegacias de Polícia no Brasil. Rio de Janeiro: Altus, CESeC, Fundação Konrad Adenauer, 2010.

BAYLEY, David; BITTNER, Edgar. The tactical choices of police patrol officers. Journal of Criminal Justice, New York, v. 14, n. 14, p. 329-348, dec. 1986.

CICOUREL, Aaron V. The Social Organization of Juvenile Justice. New York: John Wiley \& Sons Inc., 1968.

COELHO, Edmundo. Sobre Sociólogos, Pobreza e Crime. Dados - Revista de Ciências Sociais, Rio de Janeiro, v. 23, n. 3, p. 377-83, 1980.

CUNHA, José Ricardo. Direitos humanos e justiciabilidade: pesquisa no Tribunal de Justiça do Rio de Janeiro. Sur, Revista internacional de Direitos Humanos, São Paulo, v. 2, n. 3, p. 139-172, jul.-dez. 2005.

FRÜHLING, Hugo. Research on Latin American police: where do we go from here? Police practice and research: an international journal, New York, v. 10; n. 5-6; p. 465-482, out.-dez. 2009.

GARFINKEL, Harold. Studies in Ethnomethodology. Englewood Cliffs: Prentice Hall, 1967.

GIDDENS, Anthony; TURNER, Jonathan (Orgs.). Teoria Social Hoje. São Paulo: Editora da UNESP, 1999.

HOLLANDA, Cristina Buarque. Polícia e Direitos Humanos: política de segurança no primeiro governo Brizola [Rio de Janeiro: 1983-1986]. Rio de Janeiro: REVAN, 2005.

IPEA. Sistema de Indicadores de Percepção Social-Segurança Pública. Brasília, 02 de dezembro de 2010. Disponível em: <http://www.ipea.gov.br>. Acesso em: 10 dez. 2010. 
KANT DE LIMA, Roberto. Cultura Jurídica e Práticas Policiais: a tradição inquisitorial. Revista Brasileira de Ciências Sociais, São Paulo, v. 4, n. 10, p. 65-84, jun. 1989.

- Direitos civis e direitos humanos: uma tradição judiciária prérepublicana? São Paulo em Perspectiva, São Paulo, v. 18, n. 1, p. 49-59, jan.-mar. 2004.

MANNING, Peter. Policing as self-audited practice. Police practice and research: an international journal, New York, v. 10; n. 5-6, p. 451-464, out.-dez. 2009.

MISSE, Michel. Malandros, marginais e vagabundos: a acumulação social da violência no Rio de Janeiro. 1999. 413 f. Tese (Doutorado em Sociologia) - Instituto Universitário de Pesquisas do Rio de Janeiro (IUPERJ), [1999].

NASCIMENTO, Nívio Caixeta. Entre as leis e o mundo: polícia e administração de conflitos numa perspectiva comparativa. 2006. 201 f. Tese (Doutorado em Antropologia) - Departamento de Ciências Sociais, Universidade de Brasília (UNB), [2003].

PAIXÃO, Antônio Luiz. A Organização Policial numa Área Metropolitana. Dados - Revista de Ciências Sociais, Rio de Janeiro, v. 25, n. 1, p. 6385, 1982.

RAMOS, Sílvia; MUSUMECI, Leonarda. Elemento suspeito: abordagem policial e discriminação no Rio de Janeiro. Rio de Janeiro: Civilização Brasileira, 2005.

SAPORI, Luís Flávio. Administração da Justiça Criminal em uma Área Metropolitana. Revista Brasileira de Ciências Sociais, São Paulo, v. 10, n. 29, p. 143-157, out. 1995.

SCHUTZ, Alfred. Fenomenologia e Relações Sociais. Rio de Janeiro: Zahar Editores, 1979.

SOARES, Luiz Eduardo. Meu Casaco de General. São Paulo: Companhia das Letras, 2000.

SUDNOW, David. Normal Crimes: Sociological Features of the Penal Code. Social Problems, Berkeley, v. 12, n. 3, p. 255-276, winter 1965. 